\title{
The photoneuromime: An artificial visual neuron for dynamic testing of computer-controlled experiments
}

\author{
D. E. SCHWEITZER-TONG \\ Departments of Engineering Sciences, Neurobiology, and Physiology, and \\ Biomedical Engineering Center, Technological Institute \\ Northwestern University, Evanston, Illinois 60201
}

\begin{abstract}
The photoneuromime is a simple electronic device that produces frequency-modulated pulses resembling neural spike trains in response to light modulation. It simulates the linear behavior of cat retinal ganglion $\mathrm{X}$-cell receptive field centers and was designed for testing computer programs that track sensitivity to patterns generated on a raster-scan CRT. Besides providing a convenient means for testing computer programs and recording apparatus, which previously required the use of a live preparation, the neuromime is also a valuable teaching tool in sensory psychology and neuroscience.
\end{abstract}

For many years, a principal part of the research in our laboratory has been the recording of input-correlated responses of cat retinal ganglion cells to time-varying stimuli generated on a raster-scan CRT visual stimulator (Enroth-Cugell \& Robson, 1966; Frishman \& Linsenmeier, 1982; Linsenmeier, Frishman, Jakiela, \& Enroth-Cugell, 1982; Linsenmeier \& Jakiela, 1979; Schweitzer-Tong, Robson, Watson, Shou, \& EnrothCugell, 1981). Other laboratories engaged in similar research also use raster-scan CRT visual stimulators.

The apparatus employed in such work involves a number of separate instruments linked together and controlled by a computer in the feedback path. To insure that all portions of the equipment, including the computer program, function properly, it was our custom in the past to test the system in an experiment using a live preparation. Not only was such a method of testing time-consuming, especially when a defect was discovered in some part of the overall system, but it involved the unnecessary sacrifice of an animal.

We have now eliminated the need for such a living link during testing by the use of a very simple electronic simulator of the retinal ganglion cell that sufficiently closely models an actual cell to give a meaningful test of the complete system. It is the purpose of this communication to describe this electronic model, called a "neuromime" (Bergeijk, 1960; Harmon, 1961), in the hopes that it will aid other laboratories in their work and help to eliminate the use of animal preparations except when collecting actual experimental data.

I am especially grateful to J. G. Robson for his critical and constructive reading of an early draft. I would also like to thank L. Frishman, M. Levine, and F. Offner for their advice and helpful comments, and C. Enroth-Cugell for her encouragement. The author was supported by NEI New Investigator Award R23 EY 03738.
In order to simulate the response of an ideal retinal ganglion X-cell receptive field center, the photoneuromime produces a frequency modulated "spike" output that is proportional to stimulus luminance over a temporal frequency range of 0 to about $75 \mathrm{~Hz}$ (see Figure 1).

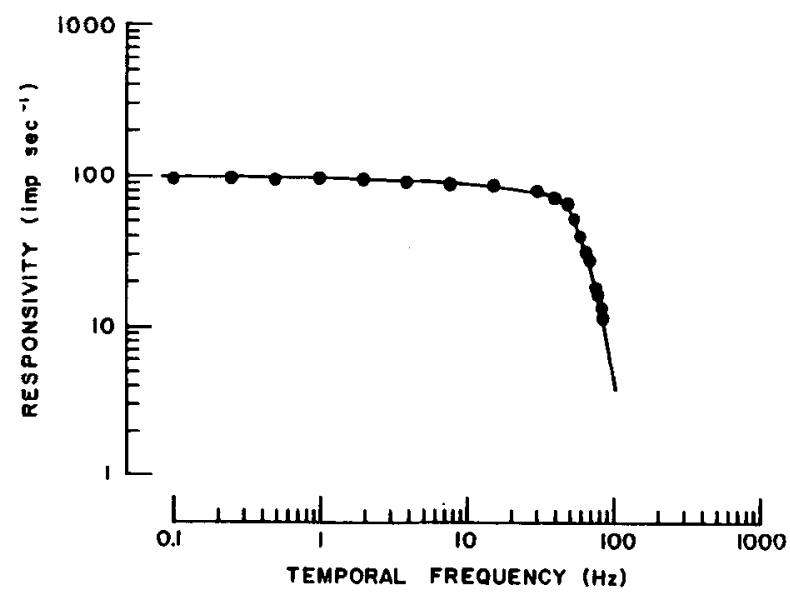

Figure 1. Temporal frequency response of the photoneuromime. The stimulus was a low spatial frequency drifting sinewave grating generated on a $21 \times 32 \mathrm{~cm}$ CRT display (Joyce Electronics, England). The CRT had a $200-\mathrm{Hz}$ frame rate and was driven by a PDP-11/04 computer that also collected and analyzed responses. Responses at each temporal frequency were collected over a 10 -sec period and compiled into average response histograms containing one complete cycle of the sinusoidal response waveform. For each histogram, the fundamental Fourier component was calculated and response amplitude was expressed as the modulation depth in impulses per second. To obtain responsivity, the measure shown on the ordinate, response amplitude was normalized by dividing response amplitude by the stimulus contrast used to elicit the response [responsivity (impulses/second) $=$ response amplitude (impulses/second) $/$ stimulus contrast ] 
This device can be constructed by anyone experienced with basic op-amp circuits.

\section{APPLICATIONS}

We have arranged for the output of the photoneuromime to travel the same signal processing path followed by spikes recorded during experiments. An auxiliary input to the spike amplifier routes the artificial "spike train" from the neuromime to gain and filtering stages, as well as to the audio monitor, Schmitt trigger, and computer. Since signals are routed through the entire recording setup (bypassing only the preamplifier built into the microdrive housing), the entire recording and data analyzing system can be easily tested prior to each experiment.

Our primary application for the photoneuromime was for testing a computer program that generates visual stimuli on the CRT display, Fourier analyzes the neural responses, and controls parameters of the display. The use of a raster-scan CRT display necessitates limiting the high-frequency responsiveness of the photosensor. Although patterns viewed on a raster-scan CRT display appear continuous in time, the display is in fact discontinuous; the entire CRT screen is painted and repainted over a hundred times per second. According to sampling theory, this "refresh" or "frame" rate should be more than twice the highest frequency generated on the display. Since under optimal conditions cat retinal ganglion cells may respond to stimulus frequencies as high as $50-80 \mathrm{~Hz}$, a frame rate of more than $160 \mathrm{~Hz}$ is required. Because the photoneuromime was expressly designed to be used with a raster-scan CRT stimulator, it incorporates low-pass filtering with a nominal cutoff frequency of about $75 \mathrm{~Hz}$ to prevent raster frame frequencies from modulating the output. The amplified and filtered analog signal, available as a second output of the neuromime, is useful when raster-scan CRT displays are used to study evoked potentials and other analog signals. It can also be used as a stimulus monitor.

The photoneuromime can also be used with visual stimulators having steady light sources, such as incandescent light bulbs, that do not have undesirable highfrequency components that require low-pass filtering. For example, the photoneuromime is compatible with optical projection systems that use transparencies for producing gratings and bars and use optical scanners and shutters to flash, drift, and/or phase reverse these stimuli. When a photoneuromime (which is not equipped with a focusing lens) is used with a projection system, its photosensor should face the light source so that the projected patterns are imaged on it directly.

In our laboratory, the photoneuromime has also been used to simulate eye displacements for testing a computer program that checks the alignment of the stimulus with the receptive field middle (Freeman, Note 1). Misalignments, caused by residual eye movements in immobilized animal preparations, are corrected by repositioning the stimulus on the CRT screen.

Yet another use of the photoneuromime is for evaluating neural models. For example, Levine (1982) has used a modified (unfiltered) photoneuromime to test his model of the processing of intrinsic and extrinsic noise in the goldfish retina. His extrinsic noise stimulus was an arc lamp modulated with Gaussian noise. The evaluation of the model progressed in two stages. First, it was established that stimulation of the photoneuromime with Gaussian noise per se did not produce the type of statistical structuring of the neuromime spike train that was observed in the maintained discharge of goldfish retinal ganglion cells. Second, it was demonstrated that the addition of filtering networks specified by the model caused the neuromime discharge to acquire the statistical structuring characteristic of ganglion cells.

Finally, the photoneuromime is very useful in the classroom. It can provide an audio-visual demonstration of the general principle of frequency coding in the nervous system. For a section specifically on the physiology of vision, the photoneuromime is especially useful for demonstrating the linear spatial summation characteristic of cat retinal ganglion X cells (EnrothCugell \& Robson, 1966; Hochstein \& Shapley, 1976). For instance, a demonstration with a bipartite field makes the concept of the "null position," a consequence of the linear spatial summation, intuitively evident.

\section{CIRCUIT DESCRIPTION}

The photoneuromime circuit accomplishes two independent tasks: (1) It attenuates high frequencies to prevent frame frequencies from modulating the output of the neuromime, and (2) it performs a voltage to frequency conversion. Provision is also made for adjusting both the ongoing firing rate and the sensitivity of the photoneuromime.

A functional block diagram of the circuit is shown in Figure 2. A photosensor feeds a variable-gain input stage incorporating a single-pole low-pass filter. The input stage is followed by a four-pole low-pass filter. Next, an adjustable offset voltage is added to the low-pass filtered signal for setting the ongoing firing rate for a particular level of mean illumination. An analog output is available at this point. Finally, the analog voltage is fed to a

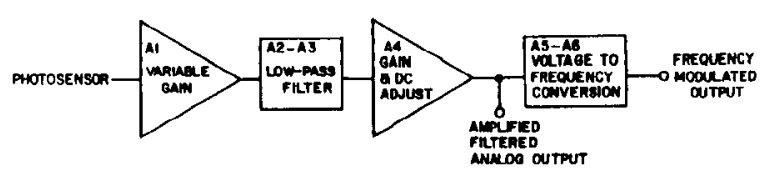

Figure 2. Block diagram of the photoneuromime. The letters in the top part of each block correspond to the sections of the detailed schematic shown in Figure 3. 

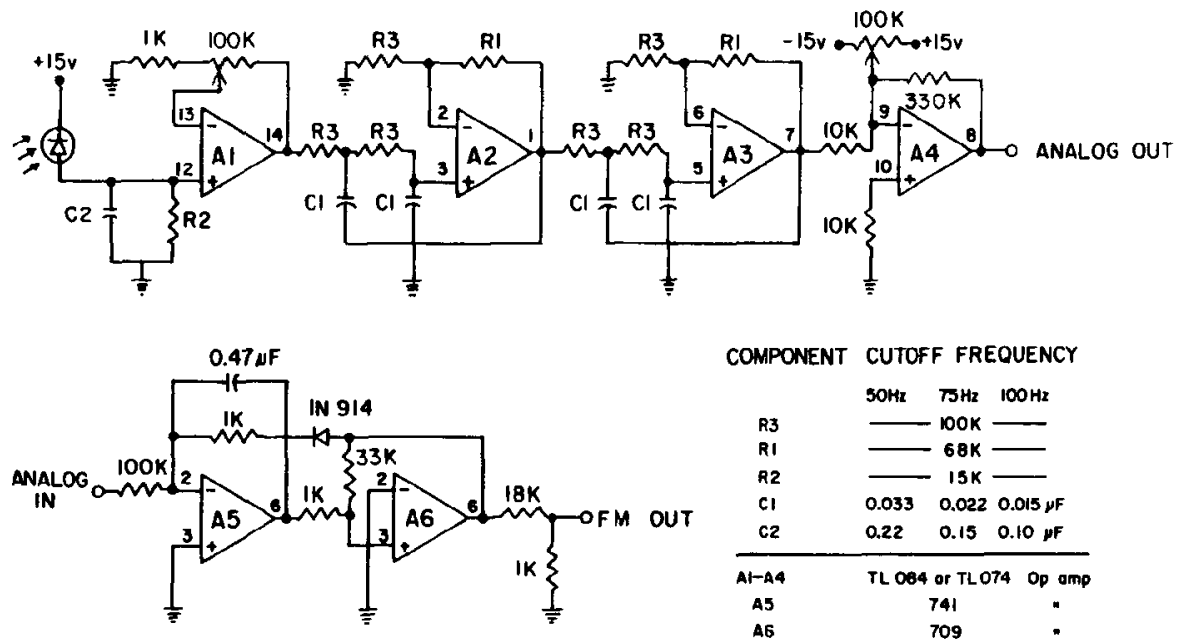

Figure 3. Circuit schematic of the photoneuromime. The photosensor is a silicon photodiode (United Detector Technology Pin-5D). Other photodiodes or phototransistors of similar sensitivity may be substituted. The inset on the right shows the resistor and capacitor values suggested for the approximate high-frequency cutoffs as listed. To ensure adequate attenuation of the frame frequency, use a cutoff frequency no higher than about one-third of the frame frequency. If necessary, one or more additional stages of two-pole low-pass filtering may be added to obtain additional 6-dB/octave high-frequency rolloff per pole. The power supply is $\pm 15 \mathrm{~V}$ (for the TL 084 and TL 074, $+V$ is at Pin 4, $-V$ at $P i n 11$; for the 741 and $709,+V$ is at $P$ in 7 , and $-V$ at $P$ in 4). The 100-KB pot associated with Al controls the gain, and the 100-KB pot at A4 controls the ongoing rate of firing.

voltage-to-frequency converter to produce a frequencymodulated output that resembles a spike train.

Figure 3 shows the circuit schematic for the complete photoneuromime. The photosensor, a silicon photodiode (UDT Pin 5D), used in the photoconductive mode varies its resistance as a function of the intensity of the light impinging on its surface. Amplifier A1 has adjustable gain using a standard op-amp configuration (see Jung, 1974; Oleksy, 1974). The fourth-order low-pass filter is obtained by cascading two second-order equalcomponent Sallen-Key filters (A2 and A3; see Lancaster, 1975 , p. 45, p. 128). The signal is level shifted and inverted by a fixed-gain summing amplifier (A4). A simple voltage-controlled oscillator, composed of an opamp integrator (A5) followed by a level-resetting comparator (A6), performs the voltage-to-frequency conversion. The output consists of fixed-amplitude pulses.

\section{ACCESSORIES AND MODIFICATIONS}

\section{Focusing System}

It is useful for some applications to add an optical system to the photoneuromime so that the image of the CRT pattern or other object can be focused on the face of the photosensor. A simple system can be constructed in which a lens equidistant from the photo. sensor and a ground glass viewing screen focuses the image on both by means of a beamsplitter. Alternatively, a versatile system could be constructed by mounting the photosensor in the film plane of a $35-\mathrm{mm}$ single-lens reflex camera equipped with a macro (close-up) and a telephoto lens.

Adding the Neuromime to an Existing Photometer An earlier version of the photoneuromime did not have its own photosensor. Instead, a commercially built photometer (United Detector Technology 40X optometer) supplied the input to the gain, filtering, and voltage-to-frequency conversion stages of the neuromime circuit. Several simple modifications were necessary to obtain a usable analog output from this optometer. A description of these modifications is available from the author.

\section{Center-Surround Antagonism}

A more elaborate version of the photoneuromime might use two optically superimposed photosensors of different sizes with additional circuitry to simulate the concentric, overlapping, antagonistic center-surround organization of cat retinal ganglion $X$ cells. It would not attempt to simulate the actual physiological system, many details of which are still unknown. Although for some teaching purposes the center-surround version would have some advantages over the simpler center version of the neuromime, for most laboratory applications the center version is adequate and simpler to construct.

\section{REFERENCE NOTE}

1. Freeman, A. Personal communication, 1982. 


\section{REFERENCES}

BeroeijK, W. A. van. Nomenclature of devices which simulate biological functions. Science, 1960, 132, 1248-1249.

Enroth-Cugell, C., \& Rosson, J. The contrast sensitivity of retinal ganglion cells of the cat. Journal of Physiology (London), $1966,187,517-552$.

Frishman, L. J., \& Lingenmeier, R. A. The effects of picrotoxin and strychnine on non-linear responses of $Y$-type cat retinal ganglion cells. Journal of Physiology (London), 1982, 324, 347363.

Harmon, L. D. Studies with artificial neurons, I: Properties and functions of an artificial neuron. Kybernetik, 1961, 1, 89-117.

Hochstein, S., \& Shaplex, R. M. Quantitative analysis of retinal ganglion cell classifications. Journal of Physiology (London), 1976, 262, 237-264.

Juna, W. G. IC op-amp cookbook. Indianapolis: Sams, 1974.

LANCAsten, D. Active filter cookbook. Indianapolis: Sams, 1975.
LEvine, M. Retinal processing of intrinsic and extrinsic noise. Journal of Neurophysiology, 1982, 40, 992-1010.

Lingenmeter, R. A., Frishman, L. J., Jakiela, H. G., \& Ennoth-Cuastl, C. Receptive field properties of cat retinal ganglion cells derived from contrast sensitivity measurements. Vision Research, 1982, 22, 1173-1183.

Linge nMe ier, R. A., \& Jakiela, H. G. Non-linear spatial summation in cat retinal ganglion cells at different background levels. Experimental Brain Research, 1979, 36, 301-309.

Olexsy, J. E. Practical solid-state circuit design. Indianapolis: Sams, 1974.

Schweitzer-Tona, D. E., Robson, J. G., Watson, A. B., Shov, T., \& Enroth-Cuael, C. Spatio-temporal properties of one class of cat retinal ganglion cells. Investigative Ophthalmology and Visual Science, 1981, 20(3), 14. (Supplement)

(Received for publication October 7, 1982; revision accepted November 16, 1982.) 